\title{
EFFECT OF INOCULATION WITH ARBUSCULAR MYCORRHIZAL FUNGUS Rhizophagus irregularis ON AUXIN CONTENT IN HIGHLY MYCOTROPHIC BLACK MEDICK UNDER LOW PHOSPHORUS IN SOIL
}

\section{A.P. YURKOV1, 2, 3, S.V. VESELOVA ${ }^{4}$, L.M. JACOBI ${ }^{1}$, G.V. STEPANOVA ${ }^{5}$, G.R. KUDOYAROVA ${ }^{6}$, M.F. SHISHOVA ${ }^{3}$}

\begin{abstract}
${ }^{1}$ All-Russian Research Institute for Agricultural Microbiology, Federal Agency of Scientific Organizations, 3, sh. Podbel'skogo, St. Petersburg, 196608 Russia, e-mail yurkovandrey@yandex.ru (corresponding author), lidijajacobi@yandex.ru;

${ }^{2}$ Russian State Hydrometeorological University, Ministry of Education and Science of the Russian Federation, 98, Malookchtinskiy pr., St. Petersburg, 195196 Russia;

${ }^{3}$ Saint-Petersburg State University, Ministry of Education and Science of the Russian Federation, 7/9, Universitetskaya nab., St. Petersburg, 199034 Russia, e-mail mshishova@mail.ru (corresponding author);

${ }^{4}$ Institute of Biochemistry and Genetics of Ufa Scientific Center RAS, Federal Agency of Scientific Organizations, 71, Ufa, Prospekt Oktyabrya, 450054 Russia, e-mail veselova75@rambler.ru;

5 V.R. Williams All-Russian Fodder Research Institute, Federal Agency of Scientific Organizations, 1, Nauchnii Gorodok, Lobnya, Moscow Province, 141055 Russia, e-mail gvstep@yandex.ru;

${ }^{6}$ Ufa Institute of Biology RAS, Federal Agency of Scientific Organizations, 69, Prospekt Oktyabrya, Ufa, 450054 Russia, e-mail guzel@anrb.ru
\end{abstract} ORCID:

Yurkov A.P. orcid.org/0000-0002-2231-6466

Kudoyarova G.R. orcid.org/0000-0001-6409-9976

The authors declare no conflict of interests

Acknowledgements:

The equipment of Resource Center of SPU Scientific Park for development of molecular and cell tecynologies (NIR № 109-98) has been used.

Supported in part by SPU (grant № 1.37.534.2016), Russian Science Foundations (grant № 16-16-00118), Russian Foundation for Basic Research (grants № 15-29-02753-ofi-m and № 15-04-04750-a)

Received October 21, 2016

\section{Abstract}

The investigation is focused on the elucidation of symbiotic effectiveness mechanisms of arbuscular mycorrhiza (AM) which is one of the most widespread symbiosis, developed between Glomeromycota fungi and $92 \%$ of land plants. The role of auxin in regulation of plant development with AM fungi symbiosis might be considered as one of such mechanisms, since this plant hormone plays a key role in root development and accelerates spore germination, intensifies the infection process and subsequent growth of the hyphae after exogenous addition. This study is aimed to identify for the first time the dynamics of endogenous indole acetic acid (IAA) concentration in roots and leaves of strongly mycotrophic black medick line (Medicago lupulina) under conditions of lowphosphorus available for plants nutrition in the soil. Analyses were carried out in the course of plant development. On day 14 after sowing (DAS), at the stage of the first true leaf development, we observed primary infection, the formation of the first arbuscules $(a, \%)$ and vesicles in roots, and the beginning of lateral root formation and primary growth response to mycorrhization manifested in the development of above-ground plant parts. On DAS 21 (the second leaf stage) there was a significant growth response to mycorrhization and arbuscule development in roots. On DAS 35, at shooting stage, the arbuscule development and active development of vesicles in roots occurred. Finally, on DAS 50 (at flowering start) the vesicles development was more active. Analysis of mycorrhization level showed that arbuscules played a key role in the formation of effective symbiosis in black medick at the stages of the first and second leaf, and the a/(100\% - a) value increased to $8.0 \pm 0.7$ and $18.5 \pm 1.3$, respectively. At later stages of shooting and flowering, their role diminished as compared to the mycelium development in the roots. The efficiency of the inoculation with AM Rhizophagus irregularis symbiotic fungi tested by weight of aboveground parts significantly increased starting with the phase of the second leaf, and remained high until the end of the experiment (above $120 \%$ ). At the same time, the weight response was absent in roots until the phase of flowering. A 2.2-fold increase in IAA level in roots at the phase of the first leaf, i.e. at the earliest stages of AM symbiosis establishing, led to inhibition of the root growth. On the other hand, the 1.8-fold increase in endogenous IAA in leaves at the second leaf phase was preceded by the elevation of AM efficiency by weight for aboveground parts, and, therefore, a shift in IAA concentration significantly intensified 
Keywords: auxin, indolilacetic acid, arbuscular mycorrhiza, symbiotic efficiency, Rhizophagus irregularis, Medicago lupulina

Arbuscular mycorrhiza (AM) is one of the most widespread natural symbiosis formed by Glomeromycota fungi and $92 \%$ of land plants. AM has a significant diversity of morphotypes and plays a key role in meadow and forest ecosystems, contributing to a significant increase in the mineral (especially phosphate) nutrition of plants $[1,2]$. AM can determine the productivity of plants and their adaptation to adverse environmental factors, especially to low amounts of nutrients in soil. It is shown that the availability of inorganic phosphorus (Pi) is a key factor in the development of AM symbiosis. With a lack of phosphorus, the root length can increase by more than $80 \%$ due to the development of the fungus [3], while the increase in availability of Pi significantly reduces the colonization rate [4]. At the same time, the development of arbuscular mycorrhiza does not always affect the length of the root, i.e. AM can affect the number of lateral roots, modulating root architecture. It is assumed that such a change leads to an increase in the number of appressoria. This hypothesis is supported by data on the induction of the lateral roots formation in Medicago truncatula during the germination of fungal spores, as well as the increase in the number of lateral roots in the lrt 1 mutant of maize during AM formation [5, 6]. Morphological and physiological modifications in the root system of plants indicate the possibility of AM-induced changes in the activity of endogenous growth regulators. According to modern concepts, many of the phytohormones are involved in the induction of the root formation during phosphate starvation [7-11]. Since auxin plays a key role in the regulation of root development, it has been suggested that this hormone can affect AM development [12, 13].

In the past few years, the role of auxin in the development of the relationship between the host plant and the AM fungus has been identified. Exogenous treatment with auxin accelerated spore germination, intensified colonization and subsequent growth of hyphae [12]. An increase in the concentration of indole acetic acid (IAA) was observed during colonization of the leek roots by AM fungi [14] that was accompanied by changes in the structure of the roots, they became more numerous, branched and shortened [15, 16]. At the same time, AM-induced accumulation of IAA was not systemic. Inoculating one part of the roots of the plant and preserving the other to be intact (split-root system) showed that the hormone was accumulated only in the roots that were directly inoculated [17]. Data have been obtained on the increase in the content of another natural auxin, indole-3-butyric acid (IBA), in AM colonization of maize roots [18, 19]; IBA is also known as a root growth regulator [20]. Decreased AM colonization was noted in mutants with disorders of auxin biosynthesis, such as "bushy" pea mutant (Pisum sativum) characterized by a low amount of IAA in shoots and roots, and a diageotropic mutant ("dia-geotropica") of tomato (Solanum lycopersicum) resistant to auxin [13,21]. Along with the increase in the amount of free IAA, a change in the content of its conjugates with sugars and amides was observed, which correlated with the accumulation of transcripts of genes encoding IAA-amido synthetase and GH3-like protein in mycorrhization of tomato roots [22]. Another mechanism for regulating the amount of free IAA can be associated with proteins that transmit the auxin of the PINs family, which ensure its polar transport in the axial organs and lateral redistribution. Mutants with a violation of the coding of these carriers had a weakened symbiosis with AM fungi, probably due to a change in the intensity of the lateral root insertion $[23,24]$.

The reported data indicates a significant dynamics of accumulation of 
auxin in plant roots during the formation of a mutually beneficial AM symbiosis. The synthesis, conjugation and transport of the hormone are involved in the process. Such a complexity seems to be the reason why in a number of cases the role of auxin was not traced or manifested itself weakly [25]. The activity of the components can vary considerably depending on the species, age and stage of plant ontogenesis.

In the present study, for the first time, an increase in the auxin content in roots was shown in the strongly mycotrophic black medick line even at the early stages of AM formation, with mycorrhiza leading to inhibition of root growth, but at the same time initiating the development of the shoot. For the first time, it was suggested that AM indirectly, through a significant increase in the amount of IAA, has a beneficial effect on the development of assimilation apparatus.

The aim of our work was to analyze the effectiveness of mycorrhiza and to evaluate the dynamics of the endogenous concentration of indole acetic acid in roots and leaves of black medick under low phosphorus in the soil.

Techniques. As a model plant, black medick (Medicago lupulina L. var. vulgaris Koch) cultivar VIC32 (MIS-1 line) was chosen. For inoculation, we used strain RCAM00320 AM of the fungus Rhizophagus intraradices (N.C. Schenck \& G.S. Sm.) C. Walker \& A. Schuessler 2010 (formerly known as Glomus intraradices N.C. Schenck \& G.S. Sm. 1982, strain CIAM8) from the collection of the All-Russian Scientific Research Institute of Agricultural Microbiology, laboratory maintenance on Plectranthus australis R. Br. [26].

In pot trials [27], we used substrates with a low content of available phosphorus $(\mathrm{Pa})$. In sod-podzol light loamy soil, $\mathrm{P}_{2} \mathrm{O}_{5}$ and $\mathrm{K}_{2} \mathrm{O}$ contents according to Kirsanov were 3.9 and $7.0 \mathrm{mg}$ per $100 \mathrm{~g}$, respectively, with organic matter of $3 \%$ and a $\mathrm{pH}_{\mathrm{KCl}}$ (after liming) of 6.1. The substrate was an air-dry soil-sand mixture in a ratio of 2:1, which was autoclaved twice (at 2 day intervals) for 1 hour at $134{ }^{\circ} \mathrm{C}$ and $2 \mathrm{~atm}$ (no toxicity after treatment). Four plants per pot were planted in pots filled with $210 \mathrm{~g}$ of soil-sand mixture, and cultivated with slow ventilation in a light box that had previously been subjected to UV sterilization. The day/night regime was $18 \mathrm{~h} / 6 \mathrm{~h}$, the air temperature was $24-26{ }^{\circ} \mathrm{C}$, and the luminous flux was $1500-1700 \mathrm{~lm}$. In the test variant, inoculation was carried out with the roots of the Plectranthus mycorrhizated by RCAM00320, and non-mycorrhizated roots of the Plectranthus were used in control.

To quantify the mycorrhiza (arbuscular abundance a, \%), maceration and staining roots of plants with AM [28] and light microscopy [29] were performed according to the description [30]. The method was improved using the advanced computer program in the Microsoft Excel shell [31]. The symbiotic efficacy of AM was determined by the gain of raw biomass of the aboveground parts and roots [32].

The auxin (IAA) level was determined in roots and aboveground parts during each phases of growth. Cotyledons were collected (day 1 after sowing), rounded and the 1st true leaf (day 14, 1st true leaf stage), rounded, 1st and 2nd true leaves (day 21, 2nd true leaf stage), 2nd, 3rd and 4th leaves (day 35, shooting stage), and three top leaves (3rd, 4th and 5th leaves) below the first inflorescence (day 50, flowering stage). The samples (lyophilized roots and leaves) were homogenized and extracted with $80 \%$ ethanol $(1: 10 \mathrm{w} / \mathrm{v})$ for $16-20$ hours at $4{ }^{\circ} \mathrm{C}$. The alcohol extract was separated by centrifugation and then evaporated to an aqueous residue. Auxins extraction into diethyl ether from the acidified aqueous residue of the alcohol extract followed by extraction into a solution of sodium carbonate and re-extraction into diethyl ether (after acidification of sodium carbonate) was carried out with a decrease in volume in each next cycle of 
extraction and re-extraction [33]. After methylation, the amount of auxins was determined by solid-phase enzyme-linked immunosorbent assay [33].

The figures show the mean $(M)$ and standard errors of the mean $( \pm$ SEM). Differences assessed according to Student's $t$-test were considered statistically significant at $\mathrm{P}<0.05$.

Results. Pot test allows us to provide optimal conditions for the development of AM and to avoid spontaneous infection with rhizobia and other symbiotic microorganisms [27]. Black medick $(2 n=16)$ is one of the most widespread species of the genus Medicago, the subgenus Lupularia (Ser.) Grossh., family Leguminosae Endl. Black medick is capable of a significant response to mycorrhiza with fungus $R$. irregularis with a low Pa content in soil [28], seed productivity is up to 2500 pcs. per plant and even more when grown in a greenhouse for reproduction. This plant species is autogamous with a genome size of $\sim 500 \mathrm{MB}$. The plants of the MlS-1 line used in the study showed signs of dwarfism in the absence of AM inoculation and at a low soil Pa. Strain RCAM00320 is an obligate symbiont [26].

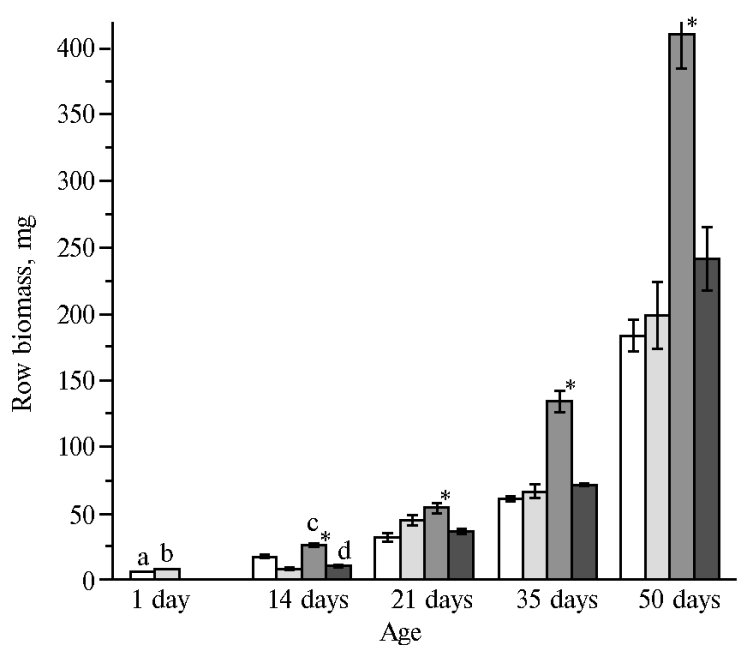

Fig. 1. The dynamics of raw biomass accumulation in the aboveground part $(\mathrm{a}, \mathrm{c})$ and roots $(\mathrm{b}, \mathrm{d})$ of black medick (Medicago lupulina) plants without inoculation $(a, b)$ in inoculation with Rhizophagus irregularis (c, d) under low available phosphorus in soil. The asterisk indicates variants in which differences with plants without inoculation (control) are statistically significant at $\mathrm{P}<0.05$. the development of vesicles is intensified [26]. Thus, these periods are most important for plant and AM formation.

At low phosphorus in soil, plants very slowly increased biomass of roots and aboveground parts in the control (Fig. 1). The dynamics of weight change was similar for both analyzed parts of plants. A significant accumulation of biomass was noted only during flowering. Inoculation of plants practically did not affect growth of the roots, but induced a multiple increase in the aboveground part biomass. The first response to mycorrhization was observed in shoots from day 14, the most significant increment of the aboveground biomass occurred during shooting.

At early stages of the plant ontogenesis, the development of $R$. irregularis was sharply intensified, primarily the formation of arbuscules. The main transporters responsible for the transition of phosphate, water and other substances are located on the branches of periarbuscular membrane. Arbuscules rate can significantly change as the plant develops, which is probably due to the limited 
life time (4-5 days) of arbuscules which degradation can take only 2.5-5.5 hours [34]. In the opinion of some authors, the plant controls the number of arbuscules by redistributing the flow of carbon-containing compounds [35]. Earlier it was shown [26] that arbuscules develop intensively at later periods. The results obtained by us, apparently, reflect the intensive development of the mycelium (Fig. 2).

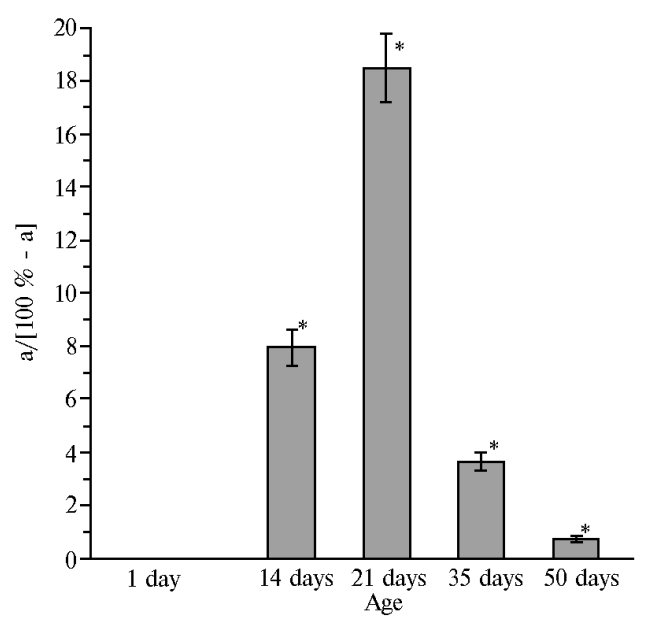

Fig. 2. The ratio a/(100 \% - a), characterizing the multiplicity of the excess of the arbuscular abundance a (\%) over the abundance of the intra-root mycelium of Rhizophagus irregularis $100 \%$ - a (\%) in black medick (Medicago lupulina) under low available phosphorus in soil. The asterisk indicates variants, the differences between which are statistically significant at $\mathrm{P}<0.05$.

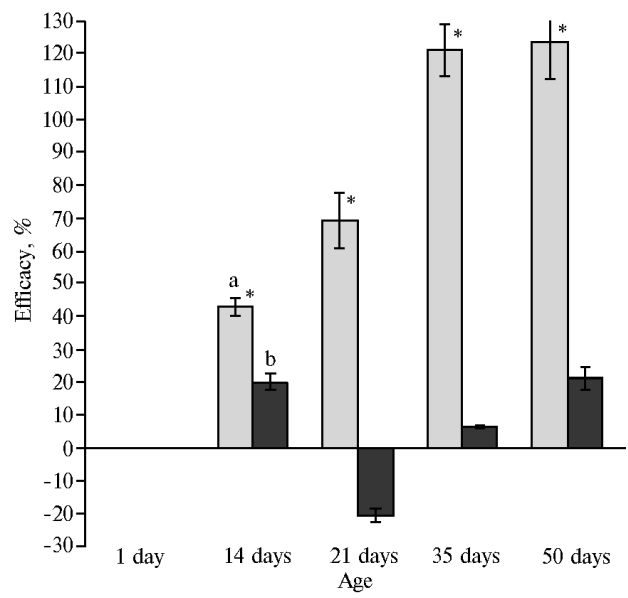

Fig. 3. Arbuscular mycorrhiza symbiotic efficacy calculated based on raw biomass of the aboveground parts (a) and roots (b), in black medick (Medicago lupulina) in inoculation with Rhizophagus irregularis (c, d) under low available phosphorus in soil. The asterisk indicates variants in which differences with plants without inoculation (control) are statistically significant at $\mathrm{P}<0.05$.

gradually increased, slightly increasing to the flowering phase (1.4-fold in the aboveground parts and 1.8-fold in the roots) (Fig. 4). It should be noted that the content of IAA in the roots was lower of root mycorrhization became negative (Fig. 3) and the increase in the number of arbuscules was not resulted from the intensive root growth. In the later stages of plant development, the efficiency of mycorrhization had small positive values. On the contrary, the symbiotic effectiveness of the aboveground part has always been positive. This index reached $120 \%$ by shooting and did not change further.

These facts are in general consistent with generally accepted beliefs about the dynamic of AM development. It is known that during mycorrhization the ratio of root and shoot biomass decreases [1, 36, 37], since the increased consumption of organic substances by roots initiates the development of photosynthetic organs. According to some data, from 4 to $20 \%$ of photoassimilates can be directed to the mycorrhizal root system [38-40]. The disruption of their transport significantly inhibits the development of AM, which can be considered as an effective regulatory mechanism. In turn, the development of arbuscules and intra-root mycelium ensures the requirements of the plant in mineral nutrition [41].

The proposed symbiotic model (strongly mycotrophic line MiS-1$R$. irregularis) made it possible to characterize the dynamic processes in the fungus and host plant. Particularly interesting are the multidirectional changes in the accumulation of shoot and root biomass and in the effectiveness of symbiosis.

The content of IAA in the raw biomass of roots without AM was low in the seedling phase and

On day 21, the effectiveness 


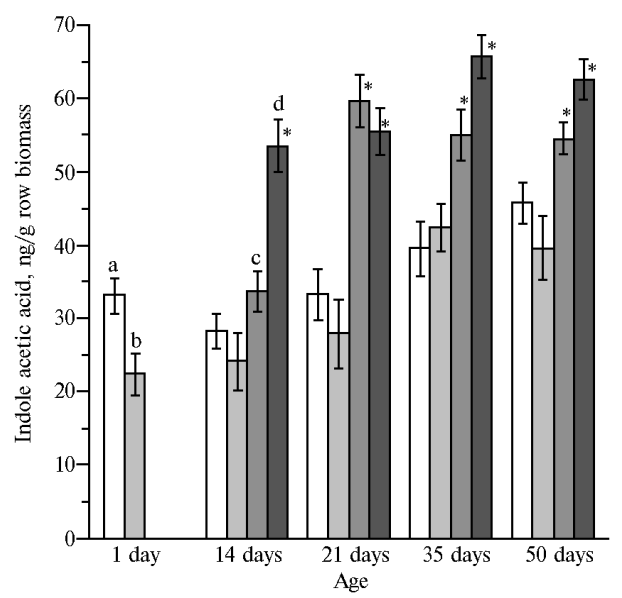

Fig. 4. Content of indole acetic acid in raw leaf biomass $(a, c)$ and roots $(b, d)$ in black medick (Medicago lupulina) plant without inoculation (a, b) and in inoculation with Rhizophagus irregularis (c, d) under low available phosphorus in soil. The asterisk indicates variants in which differences with plants without inoculation (control) are statistically significant at $\mathrm{P}<0.05$. acid in the roots and shoots was observed. An increment in the auxin level in the root occurred even at the earliest stages of arbuscular mycorrhiza formation. In this, plant inoculation practically did not affect the increase in root biomass, but led to a significant increase in biomass of the aboveground part. Probably, the attractant effect characteristic of auxin serves as a trigger mechanism for enhancing transport of carbon-containing compounds to the roots.

\section{REFEREN C ES}

1. Smit S.E., Rid D.Dzh. Mikoriznyi simbioz [Mycorrhizal symbiosis]. Moscow, 2012 (in Russ.).

2. Fusconi A. Regulation of root morphogenesis in arbuscular mycorrhizae: what role do fungal exudates, phosphate, sugars and hormones play in lateral root formation? Annals of Botany, 2014, 113: 19-33 (doi: 10.1093/aob/mct258).

3. H a r r is o n M.J. Signaling in the arbuscular mycorrhizal symbiosis. Annual Review of Microbiology, 2005, 59: 19-42 (doi: 10.1146/annurev.micro.58.030603.123749).

4. B a l z e rgu e C., Pu e ch-Pagè s V., B é c a rd G., R o c h a ng e S.F. The regulation of arbuscular mycorrhizal symbiosis by phosphate in pea involves early and systemic signaling events. Journal of Experimental Botany, 2011, 62: 1049-1060 (doi: 10.1093/jxb/erq335).

5. O lá h B., B ri è r e C., B é c a rd G., D éna ri é J., G o u g h C. Nod factors and a diffusible factor from arbuscular mycorrhizal fungi stimulate lateral root formation in Medicago truncatula via the DMI1/DMI2 signalling pathway. The Plant Journal, 2005, 44: 195-207 (doi: 10.1111/j.1365-313X.2005.02522.x).

6. Paszkowski U., B o 11 e r T. The growth defect of $l r t 1$, a maize mutant lacking lateral roots, can be complemented by symbiotic fungi or high phosphate nutrition. Planta, 2002, 214: 584-590 (doi: 10.1007/s004250100642).

7. Rouached H., Arpat A.B., Poirier Y. Regulation of phosphate starvation responses in plants: signaling players and crosstalks. Molecular Plant, 2010, 3: 288-299 (doi: 10.1093/mp/ssp120).

8. Chiou T.J., Li n S.I. Signaling network in sensing phosphate availability in plants. Annual Review of Plant Biology, 2011, 62: 185-206 (doi: 10.1146/annurev-arplant-042110-103849).

9. H a m m o nd J.P., Wh it e P.J. Sugar signaling in root responses to low phosphorus availability. Plant Physiology, 2011, 156: 1033-1040 (doi: 10.1104/pp.111.175380).

10. Sato A., Mi u r K K. Root architecture remodeling induced by phosphate starvation. Plant Signaling \& Behavior, 2011, 6: 1122-1126 (doi: 10.4161/psb.6.8.15752).

11. N i u Y.F., Chai R.S., J in G.L., W ang H., T a ng C.X., Z h a ng Y.S. Responses of root architecture development to low phosphorus availability: a review. Annals of Botany, 2013, 112: 391-408 (doi: 10.1093/aob/mcs285). 
12. Lu dwig - M ü 11 e r J. Hormonal responses in host plants triggered by arbuscular mycorrhizal fungi. In: Arbuscular mycorrhizas: physiology and function. Y. Kapulnik, H. Koltai (eds.). Springer, NY, 2010 (doi: 10.1007/978-90-481-9489-6_8).

13. Han lon M.T., Coene n C. Genetic evidence for auxin involvement in arbuscular mycorrhiza initiation. New Phytologist, 2011, 189: $701-709$ (doi: 10.1111/j.1469-8137.2010.03567.x).

14. Torelli A., Trotta A., Acerbi L., Arcidiacono G., Berta G., Branca C. IAA and ZR content in leek (Allium porrum L.), as influenced by $\mathrm{P}$ nutrition and arbuscular mycorrhizae, in relation to plant development. Plant and Soil, 2000, 226: 29-35 (doi: 10.1023/A:1026430019738).

15. Berta G., Fusconi A., Trotta A., Scannerini S. Morphogenetic modifications induced by the mycorrhizal fungus Glomus strain E3 in the root system of Allium porrum L. New Phytologist, 1990, 114: 207-215 (doi: 10.1111/j.1469-8137.1990.tb00392.x).

16. Trotta A., Carminati C., Schellenbaum L., Scannerini S., Fusconi A., Berta G. Correlation between root morphogenesis, VA mycorrhizal infection and phosphorus nutrition. In: Plant roots and their environment. B.L. McMichael, H. Person (eds.). Elsevier, Amsterdam, 1991.

17. Meixner C., Ludwig-Müller J., Miersch O., Gresshoff P., Staehelin C., Vierheilig H. Lack of mycorrhizal autoregulation and phytohormonal changes in the supernodulating soybean mutant nts 1007. Planta, 2005, 222: 709-715 (doi: 10.1007/s00425-005-0003-4).

18. Kaldorf M., Ludwig-M ülle r J. AM fungi might affect the root morphology of maize by increasing indole-3-butyric acid biosynthesis. Physiologia Plantarum, 2000, 109: 58-67 (doi: 10.1034/j.1399-3054.2000.100109.x).

19. Fitze D., Wiepninga A., Kaldorf M., Ludwig-Müller J. Auxins in the development of an arbuscular mycorrhizal symbiosis in maize. Journal of Plant Physiology, 2005, 162: 1210-1219 (doi: 10.1016/j.jplph.2005.01.014).

20. Overvoorde P., Fukaki H., B e e ckman T. Auxin control of root development. Cold Spring Harbor Perspectives in Biology, 2010, 2: a001537 (doi: 10.1101/cshperspect.a001537).

21. F o o E. Auxin influences strigolactones in pea mycorrhizal symbiosis. Journal of Plant Physiology, 2013, 170: 523-528 (doi: 10.1016/j.jplph.2012.11.002).

22. Liao D., Chen X., Chen A., Wang H., Liu J., Liu J., Gu M., Sun S., Xu G. The characterization of six auxin-induced tomato GH3 genes uncovers a member, SlGH3.4, strongly responsive to arbuscular mycorrhizal symbiosis. Plant \& Cell Physiology, 2015, 56(4): 674-687 (doi: 10.1093/pcp/pcu212).

23. Dubrovsky J.G., Napsucialy-Mendivil S., Duclercq J., Cheng Y., Shishkova S., Ivanchenko M.G., Friml J., Murphy A.S., Benková E. Auxin minimum defines a developmental window for lateral root initiation. New Phytologist, 2011, 191: 970-983 (doi: 10.1111/j.1469-8137.2011.03757.x).

24. Boivin S., Fonouni-Farde C., Frugier F. How auxin and cytokinin phytohormones modulate root microbe interactions. Frontiers in Plant Science. 2016, 7(1240): 1-12 (doi: 10.3389/fpls.2016.01240).

25. Jentschel K., Thi el D., Re hn F., Ludwig-M ülle r J. Arbuscular mycorrhiza enhances auxin levels and alters auxin biosynthesis in Tropaeolum majus during early stages of colonization. Physiologia Plantarum, 2007, 129: 320-333 (doi: 10.1111/j.1399-3054.2006.00812.x).

26. Yurkov A.P., Shis hova M.F., S e m e nov D.G. Osobennosti razvitiya lyutserny khmelevidnoi s endomikoriznym gribom [Traits of black medick development with endomycorrhizal fungus]. Saarbryukken, 2010 (in Russ.).

27. Yurkov A.P., Yakobi L.M., S tepanova G.V., Dzyubenko N.I., Provo rov N.A., Ko zhe my k o v A.P., Z a v li n A.A. Inoculation efficiency of Glomus intraradices and intrapopulation variability in plants of Medicago lupulina L. on productivity and forming of mycorrhiza. Sel'skokhozyaistvennaya biologiya [Agricultural Biology], 2007, 5: 67-74 (in Russ.).

28. Philli p s J.M., H a $\mathrm{m}$ a n D.S. Improved procedures for clearing roots and staining parasitic and vesicular-arbuscular mycorrhizal fungi for rapid assessment of infection. Transactions of the British Mycological Society, 1970, 55: 158-161 (doi: 10.1016/S0007-1536(70)80110-3).

29. Trouvelot A., Kough J.L., Gianinazzi-Pearson V. Mesure du taux de mycorhization VA d'un systume radiculaire. Recherche de méthodes ayant une signification fonctionnelle. In: Physiological and genetical aspects of mycorrhizae. V. Gianinazzi-Pearson, S. Gianinazzi (eds.). INRA-Press, Paris, 1986.

30. Yurkov A.P., Yakobi L.M., Gap e eva N.E., S te panova G.V., S his hova M.F. Ontogenez, 2015, 46(5): 313-326 (doi: 11.7868/S0475145015050109) (in Russ.).

31. Vorob'e v N.I., Yu rk ov A.P., P rov or ov N.A. Programma vychisleniya indeksov mikorizatsii kornei rastenii. Svid-vo № 2016612112 ot 12.02 .16 o gos. reg. programmy EVM. FGBNU VNIISKHM (RF). Zayavl. 21.12.2015. Opubl. 20.03.16 [The program for calculation of indexes of plant root mycorrhization. Registration certificate of computer software № 2016612112, 12.02.16. FSBSI ARRIAM (RU). Appl.: December 21, 2015. Publ. March 20, 2016] (in Russ.).

32. O d u m Yu. Osnovy ekologii [Fundamentals of ecology]. Moscow, 1975 (in Russ.). 
33. Veselov S.Yu., Kudoya rova G.R., Egutkin N.L., Gyuli-Z ade V.Z., Mus t a f i n a A.R., K of E.M. Modified solvent partitioning scheme providing increased specificity and rapidity of immunoassay for indole 3-acetic acid. Physiologia Plantarum, 1992, 86: 93-96 (doi: 0.1111/j.1399-3054.1992.tb01316.x).

34. D e n is o n R.F., K i e r s E.T. Life histories of symbiotic rhizobia and mycorrhizal fungi. Current Biology, 2011, 21(18): 775-785 (doi: 10.1016/j.cub.2011.06.018).

35. Schaarschmidt S., Gonzalez M.C., Roitsch T., Strack D., Sonnewa ld U., Hause B. Regulation of arbuscular mycorrhization by carbon. The symbiotic interaction cannot be improved by increased carbon availability accomplished by root-specifically enhanced invertase activity. Plant Physiology, 2007, 143: 1827-1840 (doi: 10.1104/pp.106.096446).

36. Scannerini S., Fusconi A., Mucciarelli M. The effect of endophytic fungi on host plant morphogenesis. In: Symbiosis: organisms and model systems. J. Seckback (ed.). Kluwer Academic Publishers, Dordrecht, 2001 (doi: 10.1007/0-306-48173-1_27).

37. S mith S.E., S mith F.A. Fresh perspectives on the roles of arbuscular mycorrhizal fungi in plant nutrition and growth. Mycologia, 2012, 104: 1-13 (doi: 10.3852/11-229).

38. D ouds D.D., Pfe ffe r P.E., S h a c ha r-H i 11 Y. Carbon partitioning, cost and metabolism of arbuscular mycorrhizae. In: Arbuscular mycorrhizas: physiology and function. Y. Kapulnick, D.D. Jr. Douds (eds.). Kluwer Academic Publishers, Dordrecht, 2000 (doi: 10.1007/978-94-017-07763_6).

39. G r a h a m J.H. Assessing costs of arbuscular mycorrhizal symbiosis agroecosystems fungi. In: Current advances in mycorrhizae research. G.K. Podila, D.D. Jr. Douds (eds.). APS Press, Saint Paul, 2000 (doi: 10.4236/oje.2014.41002).

40. B a g o B., P fe ffe r P.E., S h a c h a r -H i 11 Y. Carbon metabolism and transport in arbuscular mycorrhizas. Plant Physiology, 2000, 124(3): 949-958 (doi: 10.1104/pp.124.3.949).

41. Feddermann N., Finlay R., B olle r T., Elfstrand M. Functional diversity in arbuscular mycorrhiza - the role of gene expression, phosphorus nutrition and symbiotic efficiency. Fungal Ecology, 2010, 3: 1-8 (doi: 10.1016/j.funeco.2009.07.003).

42. Albac et e A., Ghanem M.E., Martínez-Andújar C., Acosta M., SánchezBravo J., Martínez V., Lutts S., Dodd I.C., P érez-Alfocea F. Hormonal changes in relation to biomass partitioning and shoot growth impairment in salinised tomato (Solanum lycopersicum L.) plants. Journal of Experimental Botany, 2008, 59: 4119-4131 (doi: 10.1093/jxb/ern251).

43. Vys o tsk y a L.B., Trek ozova A.W., Ku d o y a rova G.R. Effect of phosphorus starvation on hormone content and growth of barley plants. Acta Physiologiae Plantarum, 2016, 38(108): 1-6 (doi: 10.1007/s11738-016-2127-5).

44. Emel'y a ov V.V., Kirchikhina N.A., Las to chkin V.V., Chirkova T.V. Fiziologiya rastenii, 2003, 50(6): 922-929 (in Russ.). 